\title{
A RCT to evaluate a totally automated, culturally-adapted telephone counselor for increasing physical activity among physically inactive individuals in China
}

\author{
Lancelot W. H. Mui ${ }^{1}$, Robert H. Friedman ${ }^{2 *}$, Joseph T. F. Lau ${ }^{1 *}$, Ji Peng ${ }^{3}$ and Abu S. Abdullah ${ }^{2,4,5}$
}

\begin{abstract}
Background: The prevalence of diabetes in China has rapidly increased in recent years. Family history and physical inactivity are known risk factors for developing diabetes. As automated telephone-based communication is recognized as a cost-effective health promoting device, the present study aims at evaluating the efficacy of an automated telephone counselor (TLC-PA-China) for promoting physical activity to the WHO-recommended level among physically inactive family members of diabetes patients.

Methods: This study employed a parallel, two-group, non-blinded, randomized controlled trial design with equal allocation to the intervention group (TLC-PA-China), and a control group. Voluntary participants with at least one first-degree relative diagnosed with diabetes mellitus were recruited through eight Community Health Centers in Shenzhen, China. The intervention group was requested to use the system once per week during a six-month period. The control group received an information pamphlet about the benefits of regular physical activity.
\end{abstract}

Results: Two hundred ten eligible participants were randomized to TLC-PA-China ( $n=109)$ or Control $(n=101)$ groups. Using intention-to-treat analysis, the TLC-PA-China group was significantly more likely to meet the WHO physical activity recommendation than the control (GEE: $\mathrm{OR}=6.37, p<0.001$ ). The number of physically inactive people to intervene upon for one to become active was 2.84 at 3 months and 3.31 at 6 months.

Conclusions: TLC-PA-China increased physical activity levels among physically inactive adults in China who were at high risk of developing diabetes. This study lays the groundwork for application of behavioral informatics intervention in China.

Trial registration: Chinese Clinical Trial Registry ChiCTR-PRC-13003361. Registered 15 May 2013 (Retrospectively registered).

Keywords: Information and communication technologies (ICT), Disease prevention, Randomized controlled trial, Diabetes

\footnotetext{
* Correspondence: rfriedma@bu.edu; jlau@cuhk.edu.hk

${ }^{2}$ Medical Information Systems Unit, Section of General Internal Medicine, Department of Medicine, Boston University and Boston Medical Center, Boston, Massachusetts, USA

${ }^{1}$ Division of Behavioral Health and Health Promotion, JC School of Public Health and Primary Care, The Chinese University of Hong Kong, Hong Kong, SAR, China

Full list of author information is available at the end of the article
} 


\section{Background}

The World Health Organization predicted that for the next 20 years, around $11.6 \%$ of all incident diabetes cases in the world will be in China [1]. Family history and physical inactivity are known risk factors for developing diabetics [2, $3]$. Individuals who have elevated risk of developing diabetes are recommended to engage in regular physical activity [4]. In urban cities of China, such as Shenzhen, $80 \%$ of the people are physically inactive [5], 4.2\% of adults have diabetes and another $11.9 \%$ have impaired glucose tolerance [6]. In Shenzhen alone, with a population of 13.2 million (as of 2012), conventional behavior change interventions that require a human counselor have only limited reach and are not easily scalable. At the same time, there are more than 20 million registered mobile phone numbers [7] in Shenzhen. Physical activity interventions that utilize telephone networks may serve to reach the enormous Chinese population with health promotion messages.

The Telephone-Linked Care (TLC) platform is a computerized, fully automatic counseling system that delivers personalized health advice and counseling to users through the telephone [8]. A recent review recognized that physical activity intervention programs are more effective when they do not involve direct supervision or instruction components [9]. The content of these automated telephone counseling programs are based on established behavioral change theories [10]. The original TLC system for physical activity was developed for use by sedentary American people $[11,12]$.

In this study, a TLC-based system for physical activity promotion in China [TLC-PA-China] was developed, deployed, and evaluated in a randomized clinical trial in Shenzhen, China. This study explored the efficacy of TLC-PA-China in primary prevention of diabetes among physically inactive family members of diabetes patients. The goal was to increase their physical activity level to the recommended level of at least $150 \mathrm{~min}$ per week of moderate-intensity aerobic activities [4].

\section{Methods}

\section{Study design and setting}

This study employed a parallel, two-group, non-blinded, randomized controlled trial design with equal allocation to the experimental group (TLC-PA-China), and a control group. The study was carried out through eight of the Community Health Centers managed by the Shenzhen Centre for Chronic Disease Control. The Community Health Centers provide primary care services to residents in their neighborhood.

\section{Participants}

\section{Inclusion criteria}

Participants needed to have at least one first-degree relative who was diagnosed with diabetes mellitus by a physician. They must be at least 30 years of age and be physically inactive (defined as participation in less than 150 min per week of moderate or greater intensity physical activity [MOD+ PA]).

\section{Exclusion criteria}

People who were deemed unsuitable to participate in MOD+ PA activity by their physician were excluded from the study.

\section{Recruitment of study subjects}

Diabetes patients managed by the Community Health Centers were contacted by their physician and briefed about how family history and physical inactivity would increase diabetes risk of their family members. The study was introduced to the patients and invitation cards to join the study were given to those patients to take back to their immediate family members. Family members who were interested in joining contacted the Community Health Centers and were screened for physical inactivity by a research assistant using the International Physical Activity Questionnaire Short Form (IPAQ-SF) [13, 14] and by a Community Health Centre physician for their ability to perform MOD+PA. Informed consent was obtained from the participants before they joined the study.

\section{Randomization}

Block randomization (block size of 8) was employed during randomization. Two opaque envelopes were prepared by a trained field worker, one containing a card for the intervention group (TLC-PA-China) and the other containing a card for the control group. Participants were asked to draw an envelope after they consented to enroll into the study and were assigned to the group as indicated by the card inside the envelope.

\section{Sample size}

A previous TLC-PA study [12], which is also a 6 month, two-group randomized clinical trial (TLC-PA vs. control) performed in the U.S. in a sedentary general population who were patients at a multi-specialty, multi-location medical practice documented a difference between MOD+PA at 6 months follow-up favoring TLC-PA (185 \pm 154 vs. $111 \pm 155 \mathrm{~min}, p<0.01$ ) [11]. After controlling for gender and baseline activity level, $80 \%$ statistical power to detect this difference with a one-tailed $p$-value of 0.05 can be obtained with a sample size of 55 per group. We used a onetailed test as we hypothesized that the intervention group would increase physical activity as compared to the control group. Since the TLC-PA-China system is a novel technology to deliver a public health intervention in China, we over-sampled by a factor of two to accommodate for attrition. This sample size corresponds to a statistical power of $97 \%$, given that the other conditions were unchanged. 


\section{Interventions}

\section{Intervention group}

Participants who were randomized to the intervention group received the TLC-PA-China program and were requested to call the system once per week during a sixmonth period.

The TLC-PA-China system used the TLC technology to simulate face-to-face interactive counseling by a trained behavioral counselor [8]. At the beginning of each call, users entered their physical activity level for the past week. TLC-PA-China then used the digital profile (e.g. sociodemographic characteristics, behavioral constructs such as stage of change and self-efficacy for physical activity, and the person's prior responses during the same and previous TLC conversations) of each participant in its database to provide individually-tailored utterances. At the end of each call, users participated in interactive goal-negotiation and goal-setting with the TLC system (see Table 1 for an example). TLC-PA-China conversations typically lasted between 5 to $10 \mathrm{~min}$. More detailed description of the TLC system can be found in a previous paper [8]. Translation of the scripts into Mandarin Chinese was performed by the bilingual members of the research team. The content was modified to include local information that are relevant to Shenzhen, China.

\section{Control group}

Individuals randomized to the control group received an information pamphlet about the benefits of regular physical activity when they entered the study.

Outcomes and Measures.

All participants were surveyed using a structured questionnaire at baseline, 3 months, and 6 months after joining the study. The primary outcome of interest was selfreported $\mathrm{MOD}+\mathrm{PA}$ level measured using the Chinese IPAQ-SF. The IPAQ-SF was shown to have acceptable reliability $(\mathrm{ICC}=0.79)$ and validity (comparable to physical activity $\log$ ) [14]. Other variables such as socio-demographics, physical health, and smoking status were also measured using a structured questionnaire at baseline by trained research assistants at the Community Health Centers.

\section{Statistical analysis}

We applied the intention-to-treat principle for data analysis. Descriptive analyses were performed for key sociodemographic indicators such as gender, age, marital status, employment type, smoking behavior and perceived economic status. The efficacy of the TLC-PA-China system to increase participants' physical activity to the WHO-recommended level was assessed by calculating the relative risks (RR), absolute risk increase (ARI), relative risk increase (RRI), and the number needed to treat (NNT) to increase a participant's PA level to the WHO-recommended level.
Table 1 Example Script for a TLC-PA-China Call

1. \{Call Received\}

2. Introduction: "It's time to focus on another important part of managing your health: regular exercise. Participating in regular physical activity can provide many health benefits including weight loss, lower blood pressure, improved flexibility, and increased energy. If you already exercise regularly, that's great news. You'll be hearing about strategies that can help you keep up the good work. If you don't currently exercise, the information you'll hear will focus on your motivation level. Let me explain how these calls will work. Before you make each call, you'll need to figure out your current level of exercise. To do that, you'll need to keep track of two things: the number of days you engaged in moderate-intensity exercise; and the average number of minutes you exercised on each of those days. At the beginning of each call, you'll be asked to report your current level of exercise. You will need to decide how you will keep track of this information. One way to do this is to keep an exercise journal. Another way to do this is to write this information down on a calendar. When you finish giving us information about your current level of exercise, you'll hear feedback appropriate for your level of motivation. You'll also be asked to set an exercise goal to work on for the upcoming week, so give that some thought between calls. Each call ends with a suggestion that can help you become more active. With all of that in mind, let's get started!"

3. Exercise frequency assessment: "Now, I'm going to ask you how often you exercised this past week. How many days did you exercise during the past week? Include any exercise that you did for $10 \mathrm{~min}$ or more at moderate or vigorous intensity.

4. [Subject press " 0 " using telephone keypad]

5. Confirmation of answer: "You said you didn't exercise at all last week.

Is that correct? Please press "1" for yes, press "2" for no."

6. [Subject press "1" using telephone keypad]

7. Confirmation of answer: "You've told me that you're not currently active."

8. Stages of change assessment: "Are you intending to begin exercising or to increase your exercise in the near future, say within the next 6 months? Press "1" if you are intending to begin exercising or to increase your exercise within the next 6 months. If you don't intend to become more active during this time, press "2"."

9. [Subject press "2" using telephone keypad]

10. \{TLC-PA-China system records that the caller is in Precontemplation stage\}

11. $\{$ Call ends\}

Generalized estimating equations (GEE) were used to model longitudinally the effect of the TLC-PA-China system on MOD+PA levels (linear response, exchangeable working correlation matrix), and on meeting the WHO physical activity recommendation (binary response, exchangeable working correlation matrix). Both models were controlled for the effects of baseline MOD + PA level, gender and age. All statistical analyses were performed using SPSS for Windows 18.0.

\section{Results}

Figure 1 shows the flow of participants at screening, group randomization, and the two follow-up time points. Two hundred and ten participants were randomized into the two study groups with $51.9 \%(109 / 210)$ in the TLCPA-China group and $48.1 \%(101 / 210)$ in the control group. At baseline there was no significant difference between the study groups in their socio-demographic characteristics except that the proportion of males who were smokers was substantially higher than females (Table 2). 


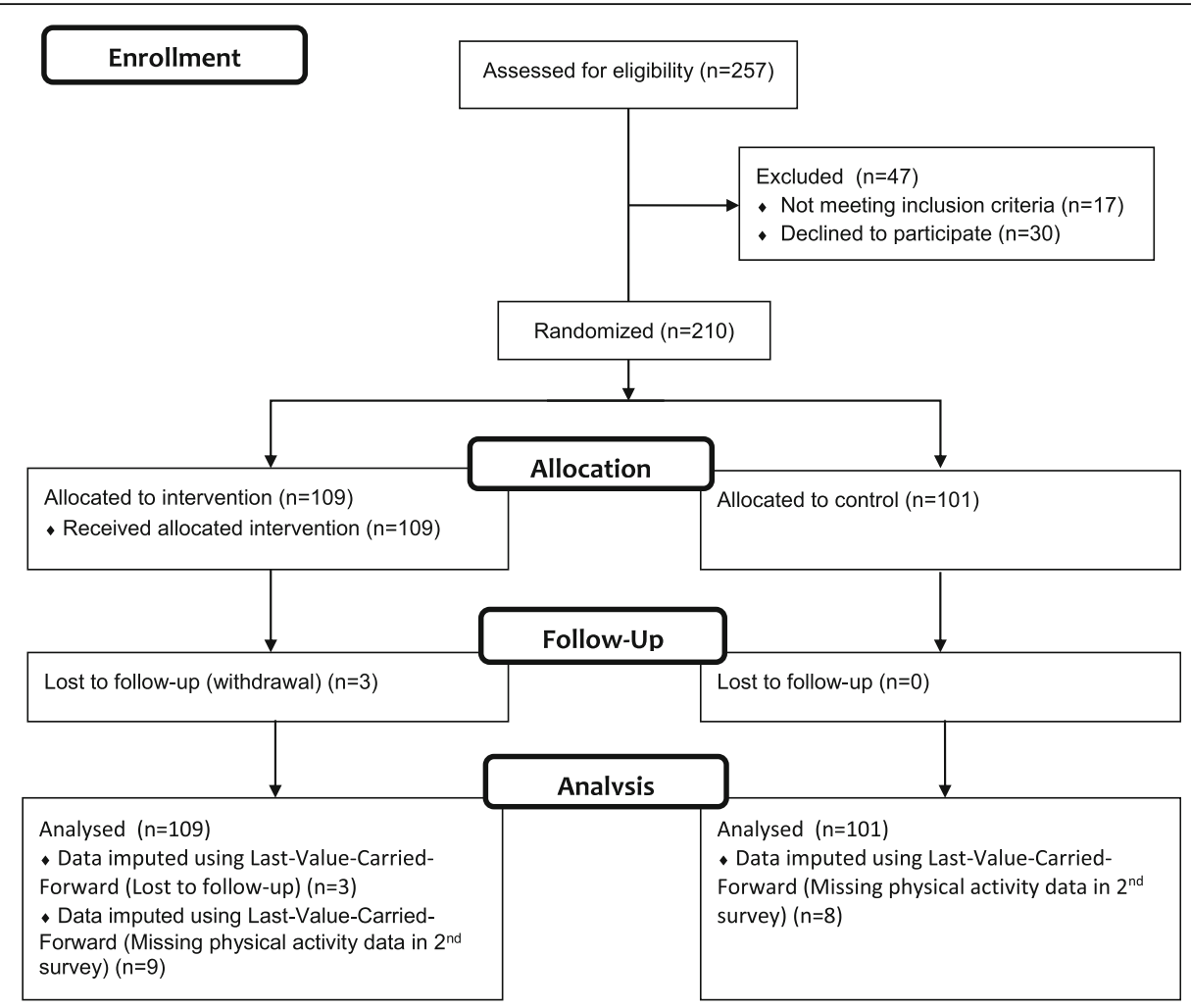

Fig. 1 Participant Flow

Likewise, the study groups' physical health status, in terms of blood pressure, body mass index, and waist-tohip ratio were also comparable (Table 3). The males, however, showed a higher level of blood pressure and were more obese than the female participants (Table 3).

Although all study subjects had less than $150 \mathrm{~min}$ MOD + PA measured at baseline by the IPAQ-SF, 19 of those who were randomized to the intervention group reported over 150 min per week of MOD+ PA to the TLC system during their first TLC call. Nonetheless, we retained all 19 subjects in the study. Differences between TLC-measured and IPAQ-measured physical activity are expected because 1) baseline administration of the IPAQ-SF preceded the first TLC call with the subjects by days, and 2) TLC assessed physical activity differently than the IPAQ-SF. We dealt with missing data using the last-value-carried-forward approach which provided a conservative estimate of the effect.

Forty percent (44/109) of the participants in the TLCPA-China group received the full dose of intervention by calling the system at least 24 times over the six-month period (Figure 2). Median number of calls to the system was 21 times. Weekly time spent on MOD+PA for both groups is shown on Figure 3. Participants who were in the TLC-PA-China group were more likely to become physically active than the control group at both 3 months $(\mathrm{RR}=6.09,95 \% \mathrm{CI}=2.99,12.79$; $\mathrm{ARI}=35.27 \%$; $\mathrm{RRI}=508.91 \%$; Table 4) and 6 months $(\mathrm{RR}=3.18,95 \%$
$\mathrm{CI}=1.91,5.42 ; \mathrm{ARI}=30.18 \% ; \mathrm{RRI}=217.69 \%$; Table 4). The effect of the TLC-PA-China system appeared to have plateaued by 3 months and the effect remained stable at 6 months. In contrast, there was a weaker, but gradual, increase in the proportion of the control group participants who became physically active over the 6 months study period. The number of participants needed to treat to increase physical activity in one participant to the WHO-recommended level was 2.84 at 3 months and 3.31 at 6 months (Table 4).

The generalized estimating equation analysis showed that at 6 months, the intervention group subjects were 7.34 times more likely to meet WHO-recommended physical activity level than the control group $(p<0.001$; Table 5), while controlling for baseline MOD+PA, gender, and age. An interaction model that adds the intervention"time interaction was also tested but the interaction term was not significant $(p>0.05$; Table 5). For participation in MOD+PA, GEE analysis with intervention"time interaction showed that by 6 months, on average intervention group subjects participated in 12.73 more minutes/wk. of MOD+PA than control group subjects. Among control group subjects, on average there was a $5.35 \mathrm{~min} / \mathrm{wk}$. monthly increase of $\mathrm{MOD}+\mathrm{PA}$ over 6 months. On the other hand, intervention group subjects increased their MOD+PA level by $19.56 \mathrm{~min} / \mathrm{wk}$. each month over the same period (Table 6). 
Table 2 Socio-demographic characteristics by treatment group or gender

\begin{tabular}{|c|c|c|c|c|c|c|c|}
\hline & $\%$ or Mean (S & & & & & & \\
\hline & All $(n=210)$ & Intervention $(n=109)$ & Control $(n=101)$ & $p^{*}$ & Male $(n=76)$ & Female $(n=134)$ & $p^{*}$ \\
\hline Gender & & & & NS & & & \\
\hline Male & 36.2 & 36.7 & 35.6 & & & & \\
\hline Female & 63.8 & 63.3 & 64.4 & & & & \\
\hline Age (year) & $41.4(7.20)$ & $41.9(7.36)$ & $40.9(7.03)$ & NS & $40.0(7.89)$ & $42.2(6.69)$ & 0.036 \\
\hline Education level & & & & NS & & & NS \\
\hline Primary or below & 1.4 & 0.9 & 2.0 & & 1.3 & 1.5 & \\
\hline Junior high & 7.1 & 7.3 & 6.9 & & 6.6 & 7.5 & \\
\hline Senior high & 39.5 & 41.3 & 37.6 & & 38.2 & 40.3 & \\
\hline Junior college & 28.1 & 24.8 & 31.7 & & 21.1 & 32.1 & \\
\hline University or above & 23.8 & 25.7 & 21.8 & & 32.9 & 18.7 & \\
\hline Marital status & & & & NS & & & NS \\
\hline Single & 5.7 & 6.4 & 5.0 & & 7.9 & 4.5 & \\
\hline Married & 85.2 & 85.3 & 85.1 & & 80.3 & 88.1 & \\
\hline Separated & 0.5 & 0.9 & 0.0 & & 1.3 & 0.0 & \\
\hline Divorced & 7.6 & 7.3 & 7.9 & & 10.5 & 6.0 & \\
\hline Widowed & 1.0 & 0.0 & 2.0 & & 0.0 & 1.5 & \\
\hline Employment type & & & & NS & & & 0.037 \\
\hline Full-time & 69.5 & 69.7 & 69.3 & & 78.9 & 64.2 & \\
\hline Part-time or temporary & 9.0 & 10.1 & 7.9 & & 10.5 & 8.2 & \\
\hline Unemployed & 10.5 & 10.1 & 10.9 & & 7.9 & 11.9 & \\
\hline Retired & 7.6 & 7.3 & 7.9 & & 1.3 & 11.2 & \\
\hline Others & 3.3 & 2.8 & 4.0 & & 1.3 & 4.5 & \\
\hline Smoking status & & & & NS & & & $<0.001$ \\
\hline Never smoker & 76.2 & 77.1 & 75.2 & & 36.8 & 98.5 & \\
\hline Current smoker & 17.6 & 16.5 & 18.8 & & 47.4 & 0.7 & \\
\hline Ex-smoker & 6.2 & 6.4 & 5.9 & & 15.8 & 0.7 & \\
\hline Doctor-rated economic status & & & & NS & & & NS \\
\hline Rich & 2.4 & 2.8 & 2.0 & & 0.0 & 3.7 & \\
\hline Comparatively rich & 22.4 & 20.2 & 24.8 & & 21.1 & 23.1 & \\
\hline Average & 60.5 & 62.4 & 58.4 & & 63.2 & 59.0 & \\
\hline Below average & 12.9 & 14.7 & 10.9 & & 14.5 & 11.9 & \\
\hline Poor & 0.5 & 0.0 & 1.0 & & 0.0 & 0.7 & \\
\hline Don't know & 1.4 & 0.0 & 3.0 & & 1.3 & 1.5 & \\
\hline Self-rated economic status & & & & NS & & & NS \\
\hline Rich & 0.5 & 0.9 & 0.0 & & 0.0 & 0.7 & \\
\hline Comparatively rich & 12.4 & 11.9 & 12.9 & & 6.6 & 15.7 & \\
\hline Average & 63.8 & 64.2 & 63.4 & & 64.5 & 63.4 & \\
\hline Below average & 21.4 & 21.1 & 21.8 & & 26.3 & 18.7 & \\
\hline Poor & 1.9 & 1.8 & 2.0 & & 2.6 & 1.5 & \\
\hline Pay out-of-pocket for medical & & & & NS & & & 0.046 \\
\hline No & 1.4 & 1.8 & 1.0 & & 3.9 & 0.0 & \\
\hline Yes & 98.6 & 98.2 & 99.0 & & 96.1 & 100.0 & \\
\hline
\end{tabular}

Study was conducted at Shenzhen, China between July and August 2009

* Student's t-test for age; Fisher's Exact Test for Pay out-of-pocket for medical, Pearson $\mathrm{X}^{2}$ for all others 
Table 3 Baseline physical health by treatment group or gender

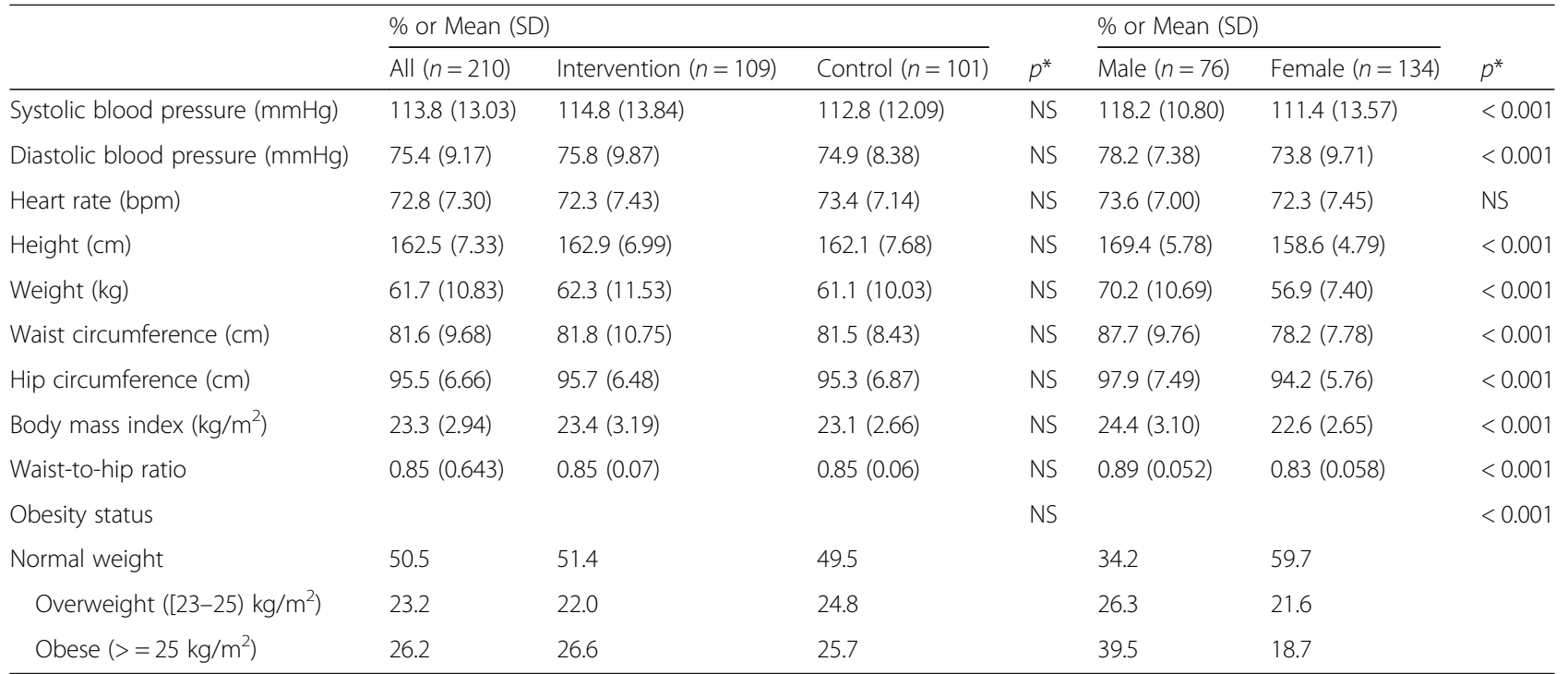

Study was conducted at Shenzhen, China between July and August 2009

NS: $p>0.05$

* Pearson $\mathrm{X}^{2}$ for obesity status, Student's t-test for all others

\section{Discussion}

Our findings showed that the TLC-PA-China system was efficacious in increasing physical activity in inactive family members of diabetes patients to levels recommended by public health authorities in China and other countries [15, 16]. The effect was substantial even though we used conservative analytic methods. Although the MOD+PA level in control group increased during the study period, possibly because of other health promotion activities in the community, the increase was substantially higher for those who used the TLC-PA-China system.

Using printed pamphlets (our control condition) to disseminate health information is a common practice because of its potential reach and ease of distribution. However, with the advancement in information and telecommunication technologies and the ubiquitous availability of the telephone, delivery of health information over the telephone has become practical. The TLC-PAChina system takes it to another level by providing not just information, but a personalized, interactive health behavior counseling intervention to the users.

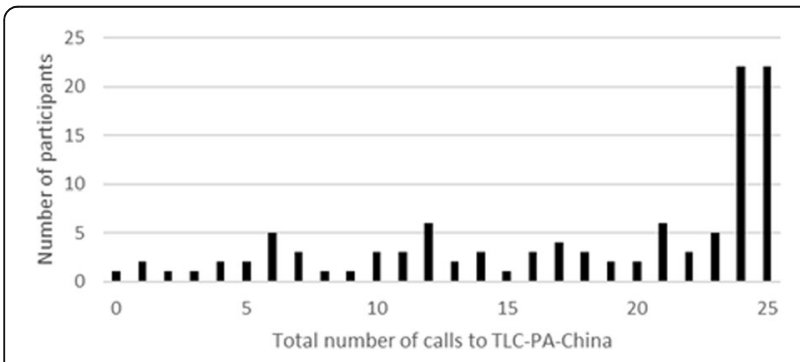

Fig. 2 TLC-PA-China Utilization
With the increasing privatization of the health care industry in China and decreasing health care funding from the Government [17], health care providers have increased the charges for their service in order to stay solvent, and resulted in substantially higher out-ofpocket payments by the patients [18]. Large out-ofpocket costs have become the primary reason for people to refuse medical care services recommended by their physician [17]. There is a very pressing need in China for health promotion and disease prevention programs that are easy to deploy and cost-effective. For every four people who were assigned to use the TLC-PA-China system in our study, one previously physically inactive person became active. If this level of physical activity can be sustained by the TLC users after the study, TLC use would have helped reduce the risk of diabetes in a substantial proportion of the participants [3]. Although the TLC-PA-China system

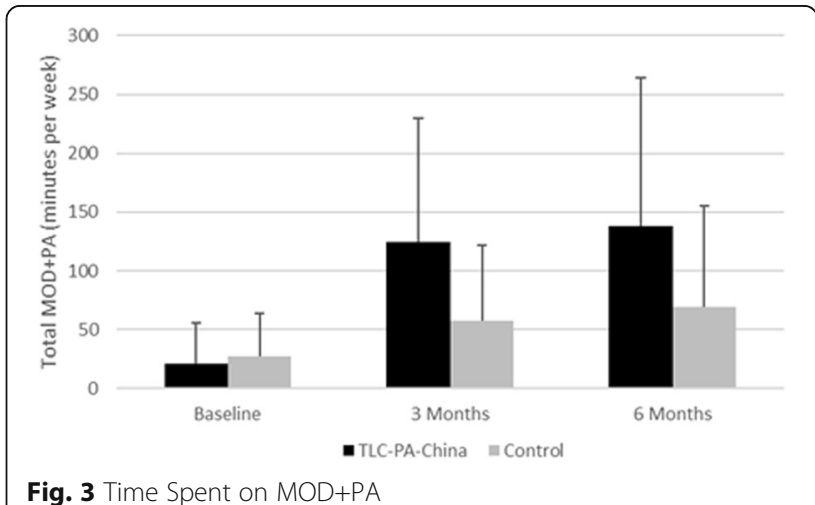


Table 4 Effectiveness of TLC-PA-China to promote physical activity

\begin{tabular}{lllll}
\hline & \multicolumn{4}{c}{$\begin{array}{c}\text { > }=150 \mathrm{~min} / \text { wk. at least moderate intensity } \\
\text { physical activity (\%) }\end{array}$} \\
\cline { 3 - 5 } Group & $\mathrm{N}$ & Baseline & 3 months & 6 months \\
\hline Control & 101 & 0.0 & 6.9 & 13.9 \\
Intervention & 109 & 0.0 & 42.2 & 44.0 \\
& & & $\mathrm{RR}(95 \% \mathrm{Cl})=6.09$ & $\mathrm{RR}(95 \% \mathrm{Cl})=3.18$ \\
& & $(2.99,12.79)$ & $(1.91,5.42)$ \\
& & $\mathrm{ARI}=35.27 \%$ & $\mathrm{ARI}=30.18 \%$ \\
& & $\mathrm{RRI}=508.91 \%$ & $\mathrm{RRI}=217.69 \%$ \\
& & $\mathrm{NNT}=2.84$ & $\mathrm{NNT}=3.31$ \\
& & &
\end{tabular}

Study was conducted at Shenzhen, China between July and August 2009 $R R$ Relative Risk, ARI Absolute Risk Increase, RRI Relative Risk Increase, NNT Number Needed to Treat

was only tested in an urban setting, the increasing urbanization in China and other countries makes this a very promising approach. In addition, given the importance of physical activity in reducing the growing burden of diabetes and obesity in rural settings, this TLC-PA-China prototype should also be adapted and tested in rural settings. While they do not usually have access to health promotion experts nearby, at least $96 \%$ of people living in rural villages in China have access to mobile telephones [19]. In addition, the use of the TLC-PA-China system does not require the user to be able to read Chinese, which is advantageous in rural China where as many as $65 \%$ of the population is unable to read [20]. Since Mandarin is the spoken language throughout the country in both rural and urban areas, TLC-PA-China's use of spoken language eliminates, or substantially reduces, the problem of implementing public health programs using printed materials. Implementation of TLC-PAChina in both urban and rural areas in China with very large numbers of at-risk relatives of diabetes patients would dramatically improve the costeffectiveness of the intervention. Most of the costs of a TLC system are capital costs for the system's computer and telecommunication hardware and software, but the operating cost of the system is very low and requires minimal manpower support [8].

The use of pre-recorded messages improves the fidelity of the intervention since it removes the known variability in the performance and quality of human counselors [21, 22]. Automatic information hotline systems are often criticized for their inflexibility and lack of options for user feedback. The TLC-PA-China system is tailored to the user's needs and is always available to them. The rapid adoption of mobile phones in China, from only 6.72 lines per 100 inhabitants in 2001 [23] to 73.6 lines per 100 inhabitants in 2012 [24] allows most people in China to access the TLC-PA-China system. The ability to deliver the program through this accessible and inexpensive platform makes it practical for use in China's public health system to address the rapid increase in sedentary behavior in the country. There is a dearth of effective interventions to fight the rapid increase in lifestyle-related chronic disease in China and other developing countries $[25,26]$. The TLC-PA-China approach could also be used for changing other potentially modifiable behavioral risk factors for disease (e.g. cigarette smoking and unhealthy diets).

The current study was performed in a single city in China with a relatively small group of individuals who were at higher risk of developing diabetes than the general population. After this efficacy study, the next logical step is to evaluate TLC-PA-China in an effectiveness study to determine how it functions in actual practice, and eventually in real world implementation in different settings and populations across China and beyond.

The main drawback of any automated system, such as the TLC platform, is the inability of the system's designers to anticipate all the issues and situations that users face. This has not been practically important since the health behavior change models used in TLC programs cover the principal factors that affect a person's health behavior and the principal situations that humans find themselves in with respect to their health behavior

Table 5 Longitudinal modeling of meeting physical activity recommendation using generalized estimating equation

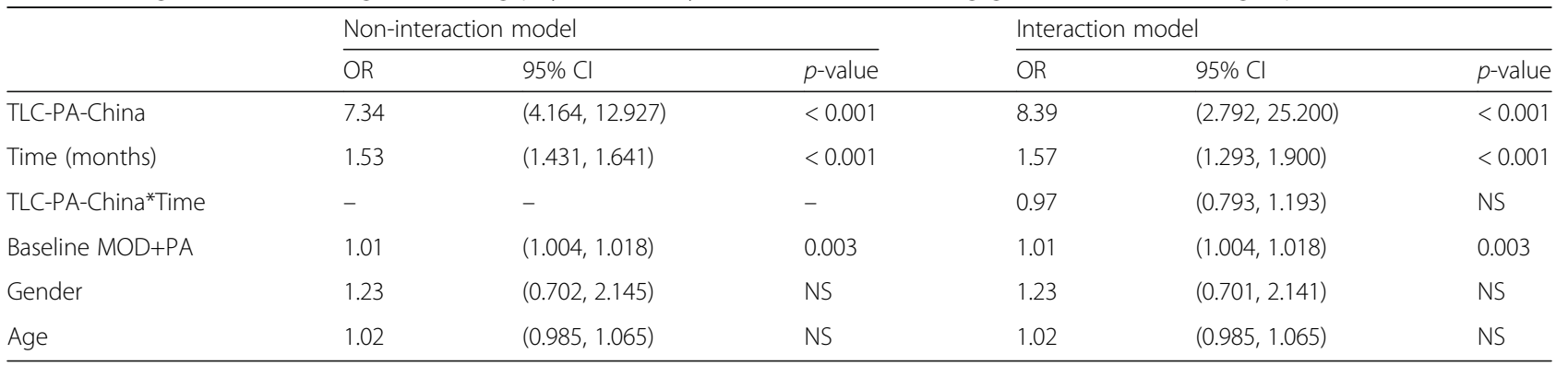

Study was conducted at Shenzhen, China between July and August 2009

NS: Not significant at $a=0.05$

Note Results are estimated for a binary outcome with logit link function and exchangeable working correlations

The asterisks indicate which variables are involved in the interaction 
Table 6 Longitudinal modeling of MOD+PA level using generalized estimating equation

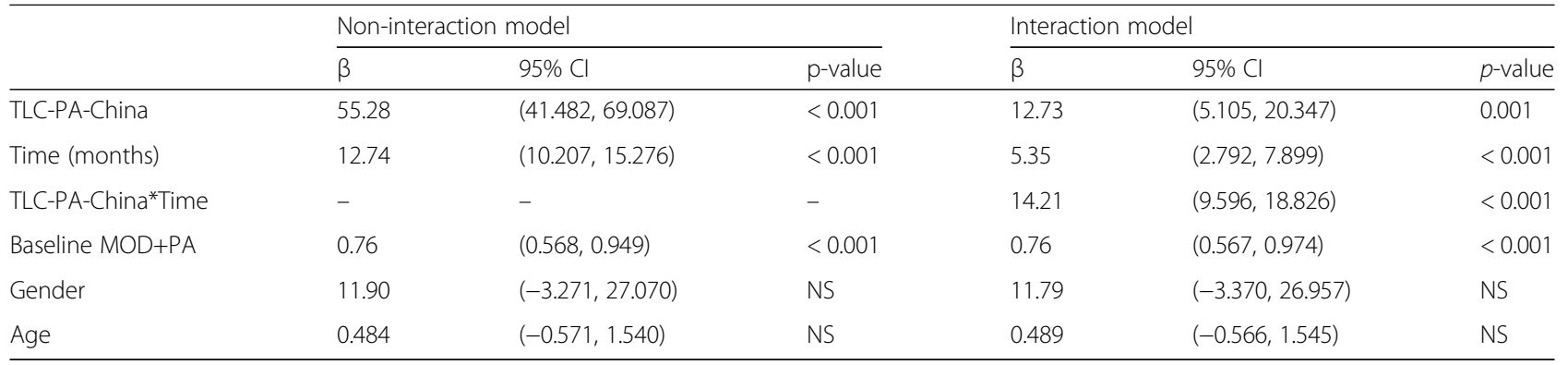

Study was conducted at Shenzhen, China between July and August 2009

NS: Not significant at $a=0.05$

Note Results are estimated for a linear outcome and exchangeable working correlations

The asterisks indicate which variables are involved in the interaction

[27]. Another potential limitation of the TLC-PA-China system is the reliance on user self-report of physical activity. In future implementation of the system in China, an objective measure of physical activity such as a pedometer or accelerometer can be used [12]. Participants in this study expressed interest in participating, so the results may not generalize to individuals who are not motivated to change their physical activity behavior. Finally, the long-term effectiveness of the TLC-PAChina system is still unclear because the program only ran for 6 months. However, in a U.S. study of TLC-PA, intervention effects of a 6-month intervention were sustained at 12 and 18 months follow up [11, 28].

\section{Conclusions}

This study introduced the behavioral informatics approach to health promotion into China. TLC-PAChina is an effective and low-cost intervention to increase the physical activity level of people at higher risk of developing diabetes in China. The monetary and time costs to participants are minimal because the automated system uses the existing telephone network to deliver the intervention with around-the-clock access. Further studies are needed to determine the long-term effectiveness of this approach, as well as to explore the effectiveness of applying this technology in routine practice in both urban and rural China. Application of the TLC platform for other behavioral health interventions in China also warrants further exploration [29, 30]. The popularity of smartphones opens up future opportunities for the TLC platform to interact with smartphone users through interactive apps.

\footnotetext{
Abbreviations

ARI: Absolute risk increase; GEE: Generalized estimating equations; IPAQSF: International physical activity questionnaire short form; MOD+ PA: Moderate or greater intensity physical activity; NNT: Number needed to treat; RR: Relative risks; RRI: Relative risk increase; TLC: Telephone-linked care; TLC-PA-China: TLC-based system for physical activity promotion in China; WHO: World Health Organization
}

\section{Acknowledgements}

The authors acknowledge the contributions of Annemarie Rigas, Benjamin Bassey, Paulie Pena and Albert Cheung for technical assistance in developing TLC-PA-China. The authors also acknowledge Crystal Lu for assistance in project management and evaluation.

\section{Funding}

This work was supported by a grant from the Fogarty International Center, National Institute of Health (1R03TW007655) to Dr. Friedman. The funding body has no role in the design of the study and collection, analysis, and interpretation of data and in the writing the manuscript.

\section{Availability of data and materials}

The datasets used and/or analysed during the current study are available from the corresponding author on reasonable request.

\section{Authors' contributions}

LM analysed and interpreted the data, and was a major contributor in writing the manuscript. RF developed the TLC technology platform, and contributed to manuscript writing. JL interpreted the data and contributed to manuscript writing. JP provided access to the subjects and interpretation of results. AA provided support in development of the TLC-PA-China system, and contributed to manuscript writing. All authors read and approved the final manuscript.

\section{Ethics approval and consent to participate}

The study protocol was approved by the Joint Chinese University of Hong Kong - New Territories East Cluster Clinical Research Ethics Committee (Ref: CRE-2007.424). Written informed consent was obtained from all participants before they join the study.

Consent for publication

Not applicable.

\section{Competing interests}

The authors declare that they have no competing interests.

\section{Publisher's Note}

Springer Nature remains neutral with regard to jurisdictional claims in published maps and institutional affiliations.

\section{Author details}

${ }^{1}$ Division of Behavioral Health and Health Promotion, JC School of Public Health and Primary Care, The Chinese University of Hong Kong, Hong Kong, SAR, China. ${ }^{2}$ Medical Information Systems Unit, Section of General Internal Medicine, Department of Medicine, Boston University and Boston Medical Center, Boston, Massachusetts, USA. ${ }^{3}$ Shenzhen Center for Chronic Disease Control, Shenzhen, China. ${ }^{4} \mathrm{Global}$ Health Program, Duke Kunshan University, Kunshan, China. ${ }^{5}$ Duke Global Health Institute, Duke University, Durham, North Carolina, USA. 
Received: 10 July 2017 Accepted: 28 March 2018

Published online: 26 June 2018

\section{References}

1. World Health Organization. Country and regional data on diabetes. Geneva: World Health Organization; 2012.

2. Gloyn AL, McCarthy MI. The genetics of type 2 diabetes. Best Pract Res Clin Endocrinol Metab. 2001;15:293-308.

3. Jeon CY, Lokken RP, Hu FB, van Dam RM. Physical activity of moderate intensity and risk of type 2 diabetes: a systematic review. Diabetes Care. 2007;30:744-52.

4. American Diabetes Association. Standards of medical care in diabetes-2014. Diabetes Care. 2014;37(Suppl 1):S14-80.

5. Reynolds K, Gu D, Muntner P, Wu X, Chen J, Huang G, et al. Geographic variations in the prevalence, awareness, treatment and control of hypertension in China. J Hypertens. 2003;21:1273-81.

6. Peng J, Zhou H, Cheng J, Luo B, Yang R, Li Y, et al. Epidemiological feature on diabetes mellitus among permanent inhabitant in the special economic zone of Shenzhen. Zhonghua liu xing bing xue za zhi. 2000;21:114-6.

7. [Shenzhen 2010 Population Economic and Social Development Statistical Bulletin]. Shenzhen: Shenzhen Municipal Statistic Bureau; 2010.

8. Friedman $\mathrm{RH}$, Stollerman JE, Mahoney DM, Rozenblyum L. The virtual visit: using telecommunications technology to take care of patients. J Am Med Inform Assoc. 1997:4:413-25.

9. Garrett S, Elley CR, Rose SB, O'Dea D, Lawton BA, Dowell AC. Are physical activity interventions in primary care and the community cost-effective? A systematic review of the evidence. Br J Gen Pract. 2011;61:e125-33.

10. Glanz K, Rimer BK, Lewis FM, editors. Health behavior and health education: theory, research, and practice. 3rd ed. San Francisco: Jossey-Bass; 2002.

11. King AC, Friedman R, Marcus B, Castro C, Napolitano M, Ahn D, et al. Ongoing physical activity advice by humans versus computers: the community health advice by telephone (CHAT) trial. Health Psychol. 2007;26:718-27.

12. Pinto BM, Friedman $R$, Marcus BH, Kelley $H$, Tennstedt S, Gillman MW. Effects of a computer-based, telephone-counseling system on physical activity. Am J Prev Med. 2002;23:113-20.

13. Deng H, Macfarlane D, Thomas G, Lao X, Jiang C, Cheng K, et al. Reliability and validity of the IPAQ-Chinese: the Guangzhou biobank cohort study. Med Sci Sports Exerc. 2008;40:303-7.

14. Macfarlane DJ, Lee CCY, Ho EYK, Chan KL, Chan DTS. Reliability and validity of the Chinese version of IPAQ (short, last 7 days). J Sci Med Sport. 2007;10:45-51.

15. [China Guidelines for Diabetes]. Chinese Diabetes Society; 2009. Available from: http://www.diab.net.cn/uploadfile/ueditor/file/20160811/ 6360650719121500001193729.pdf

16. World Health Organization. Global recommendations on physical activity for health. Geneva: World Health Organization; 2010.

17. Office of the World Health Organization Representative in China, Social Development Department of China State Council Development Research Center. China: health, poverty and economic development. Beijing: World Health Organization; 2005.

18. Ma J, Lu M, Quan H. From a national, centrally planned health system to a system based on the market: lessons from China. Health Aff. 2008;27:937-48.

19. Xinhua News Agency. $96 \%$ Village Telephone Coverage Congratulated. China.org.cn, 28 Nov 2005. http://www.china.org.cn/english/2005/Nov/ 150130.htm. Accessed 4 May 2012.

20. Fan $S$, Zhang $L$, Zhang $X$. Reforms, investment, and poverty in rural China. Economic development and cultural change. The University of Chicago Press. 2004;52:395-421.

21. Friedman $\mathrm{RH}$. Automated telephone conversations to assess health behavior and deliver behavioral interventions. J Med Syst. 1998;22:95-102.

22. Noell J, Glasgow RE. Interactive technology applications for behavioral counseling: issues and opportunities for health care settings. Am J Prev Med. 1999;17:269-74.

23. International Telecommunication Union. Yearbook of Statistics, Telecommunication/ICT Indicators (Chronological Time Series 2001-2010). 2011. http://handle.itu.int/11.1002/pub/80507b19-en

24. [Telecommunication industry major indicators for march 2012] [Chinese]. Beijing: Ministry of Industry and Information Technology of the People's Republic of China; 2012. Accessed 4 May 2012.

25. World Health Organization. Global status report on noncommunicable diseases 2010. Geneva: World Health Organization; 2011.
26. Yang H, Li X, Stanton B, Liu H, Liu H, Wang N, et al. Heterosexual transmission of HIV in China: a systematic review of behavioral studies in the past two decades. Sex Transm Dis. 2005;32:270-80.

27. King AC, Friedman R, Marcus B, Castro C, Forsyth L, Napolitano M, et al. Harnessing motivational forces in the promotion of physical activity: the community health advice by telephone (CHAT) project. Health Educ Res. 2002:17:627-36.

28. King AC, Hekler EB, Castro CM, Buman MP, Marcus BH, Friedman RH, et al. Exercise advice by humans versus computers: maintenance effects at 18 months. Health Psychol. 2014;33:192-6.

29. Migneault JP, Dedier JJ, Wright JA, Heeren T, Campbell MK, Morisky $D E$, et al. A culturally adapted telecommunication system to improve physical activity, diet quality, and medication adherence among hypertensive African-Americans: a randomized controlled trial. Ann Behav Med. 2012:43:62-73.

30. Mooney KH, Beck SL, Friedman RH, Farzanfar R. Telephone-linked care for cancer symptom monitoring: a pilot study. Cancer Pract. 2002;10:147-54.

\section{Submit your next manuscript to BioMed Central and we will help you at every step:}

- We accept pre-submission inquiries

- Our selector tool helps you to find the most relevant journal

- We provide round the clock customer support

- Convenient online submission

- Thorough peer review

- Inclusion in PubMed and all major indexing services

- Maximum visibility for your research

Submit your manuscript at www.biomedcentral.com/submit 